\title{
Improved Thermal Stability and Wettability Behavior of Thermoplastic Polyurethane / Barium Metaborate Composites
}

\author{
Emre Baştürk ${ }^{a}$, Seyfullah Madakbaş ${ }^{a *}$, Memet Vezir Kahraman ${ }^{a}$
}

${ }^{a}$ Department of Chemistry, Marmara University, 34722, Istanbul, Turkey

Received: September 24, 2015; Revised: December 17, 2015; Accepted: January 11, 2016

\begin{abstract}
In this paper, it was targeted to the enhance thermal stability and wettability behavior of thermoplastic polyurethane (TPU) by adding barium metaborate. TPU-Barium metaborate composites were prepared by adding various proportions of barium metaborate to TPU. The chemical structures of the composites were characterised by fourier transform infrared spectroscopy (FTIR) and X-ray diffraction (XRD) analysis. All prepared composites have extremely high Tg and thermal stability as determined from DSC and TGA analysis. All composite materials have the Tg ranging from 15 to $35^{\circ} \mathrm{C}$. The surface morphologies of the composites were investigated by a scanning electron microscopy. Mechanical properties of the samples were characterized with stress-strain test. Hydrophobicity of the samples was determined by the contact angle measurements. The obtained results proved that thermal, hydrophobic and mechanical properties were improved.
\end{abstract}

Keywords: Barium metaborate, thermoplastic polyurethane (TPU), polymer composite, surface properties

\section{Introduction}

Thermoplastic polyurethane (TPU) is a multi-phase block copolymer that is created when three basic raw materials are combined together in a specific way. ${ }^{1}$ Polyurethanes are among the most significant class of polymers. Polyurethanes are regarded linear segmented polymers because they are constituted of alternating sequences of "hard" and "soft" segments that phase separate into polymer chains. ${ }^{2}$ Polyols give the high flexibility to the backbone of the polymer chains. Thus they are called soft segments. Conversely, isocyanete and chain-extender components give rigidity to the polymer chains and are called hard segments. ${ }^{3,4}$

Thermoplastic polyurethane (TPU) has many excellent properties including high strength, high elongation to break and good abrasion resistance. It has many applications such as automotive instrument panels, power tools, sporting goods, medical devices, footwear, inflatable rafts and a variety of extruded film, sheet and profile applications. TPU is also a popular material found in mobile electronic devices. ${ }^{5-7}$

Polymer composites combine and maintain multiphase to produced by combining polymer resins such as polyurethanes, epoxy, with fillers and fibers to produce a bulk polymer material with improved mechanical, chemical and thermal properties relative to the parent materials is a rapidly expanding field. In some of the polymeric composites, inorganic fillers are dispersed in a polymer matrix resulting in tremendous improvement in the performance of the polymer. Fillers are often used to provide bulk to the material, reduce cost, lower bulk density or to produce aesthetic features. Fibres are used to reinforce the polymer and improve mechanical properties such as stiffness and strength. ${ }^{8-10}$

*e-mail: smadakbas@marmara.edu.tr
Thus, in recent years, in order to improve several properties of thermoplastic polyurethane (TPU) and preparation of (TPU) composites have become of great very important. Multiwalled carbon nanotubes, ${ }^{11}$ aramid-short-fiber, ${ }^{12}$ kenaf fibre, ${ }^{13}$ nanosilicate,,${ }^{14}$ graphene, ${ }^{15}$ nano-sized hexagonal boron nitride ${ }^{16}$ and mica $^{17}$ are only a small part of the inorganic additives used in thermoplastic polyurethane composites.

Barium borate is an inorganic compound, a borate of barium with a chemical formula $\mathrm{BaB}_{2} \mathrm{O}_{4} \cdot \mathrm{H}_{2} \mathrm{O}$ or $\mathrm{Ba}\left(\mathrm{BO}_{2}\right)_{2}$. $\mathrm{H}_{2} \mathrm{O}$. It is available as a hydrate or dehydrated form, as white powder or colourless crystals. It is used as an additive to paints as flame retardant, mold inhibitor, and corrosion inhibitor. It is also used as a white pigment. Barium metaborate is a microbiocide/microbiostat used as an industrial preservative in the manufacturing process of paints, paper/paper products, industrial adhesives and coatings. ${ }^{18}$

In this study is concerned with the preparation of TPU-Barium metaborate composites and to investigate the thermal and mechanical properties of these composite materials. The chemical structures of the composite materials were investigated by Fourier transform infrared spectroscopy (FTIR). X-ray diffraction (XRD) analyses of the composite materials were carried out. Thermal properties of the composites were determined by thermogravimetric analysis (TGA) and differential scanning calorimetry (DSC). Mechanical properties of the samples were characterized with stress-strain test. Hydrophobicity of the samples was determined by the contact angle measurements. The surface morphologies of the composite materials were investigated by scanning electron microscopy (SEM). 


\section{Materials and Methods}

\subsection{Materials}

TPU used in the study was a Adipate Ester Polyurethane (LARIPUR ${ }^{\circledast}$ LPR6325), kindly donated by local supplier. Barium metaborate monohydrate was purchased from Alfa Aesar. Chemical formulas of barium metaborate monohydrate is as follows: $\mathrm{Ba}\left(\mathrm{BO}_{2}\right)_{2} \cdot \mathrm{H}_{2} \mathrm{O}$. Dimethylformamide was purchased from Merck and it was used as a solvent. All chemicals were high grade reagents and were used as they were received.

\subsection{Preparation of composite materials}

TPU-Barium metaborate composites were prepared by using a solvent casting technique. First, TPU was dissolved in dimethylformamide at $80^{\circ} \mathrm{C}$. Then different amounts of barium metaborate were added to the dimethylformamide solution and stirred to homogenization. After $4 \mathrm{~h}$ period hot solutions were poured in Petri dishes. Samples were then dried in vacuum at $60{ }^{\circ} \mathrm{C}$ for $24 \mathrm{~h}$. Composites were obtained as white and transparent films. Table 1 shows the composition of the films.

\subsection{Measurements}

FT-IR spectrum was measured on Perkin-Elmer Spectrum 100 ATR-FTIR spectrophotometer. The conditions of analysis were as follows: resolution $8 \mathrm{~cm}^{-1}$ and a frequency range of $400-4000 \mathrm{~cm}^{-1}$. XRD analysis were carried out by using a Rigaku Dmax 2200 model diffractometer using $\mathrm{CuK \alpha}$ $\left(\lambda=1.5406 \mathrm{~A}^{\circ}\right)$ radiation. The diffraction pattern was recorded in terms of $2 \theta$ in the range of $0-70^{\circ}$. Thermogravimetric analyses (TGA) of the composite materials were performed using a Perkin-Elmer Thermogravimetric Analyzer Pyris 1 TGA model. Samples were run from 30 to $750{ }^{\circ} \mathrm{C}$ with heating rate of $10^{\circ} \mathrm{C} / \mathrm{min}$ under nitrogen atmosphere. DSC measurements were performed by using Pyris Diamond DSC. Samples were run from -30 to $100^{\circ} \mathrm{C}$ with a heating rate of $10{ }^{\circ} \mathrm{C} / \mathrm{min}$. Mechanical properties of the composites were determined by standard tensile stress-strain tests to measure the modulus $(\mathrm{E})$, ultimate tensile strength $(\delta)$ and elongation at break $(\varepsilon)$. Standard tensile stress-strain experiments were performed at room temperature on a Materials Testing Machine Z010/TN2S, using a crosshead speed of $2 \mathrm{~mm} / \mathrm{min}$. Standard of ASTM D3039 was used in the testing of mechanical properties of composites. The test specimen size was $60 \times 10 \times 1 \mathrm{~mm}$. Wettability characteristics of composites were performed on Kruss (Easy Drop DSA-2) tensiometer. A sessile drop method was used to measure a contact angle $(\theta)$ with a 3-5 $\mu$ l distilled water drop, which was

Table 1. The composition of the TPU-Barium metaborate composites.

\begin{tabular}{ccccc}
\hline Sample & DMF (ml) & TPU (g) & $\begin{array}{c}\text { Barium } \\
\text { Metaborate } \\
\text { (g) }\end{array}$ & $\begin{array}{c}\text { Barium } \\
\text { Metaborate } \\
\mathbf{( \% )}\end{array}$ \\
\hline F0 & 10 & 3 & - & 0 \\
F1 & 10 & 3 & 0.03 & 1 \\
F2 & 10 & 3 & 0.09 & 3 \\
F3 & 10 & 3 & 0.15 & 5 \\
F4 & 10 & 3 & 0.21 & 7 \\
\hline
\end{tabular}

applied to the surface by a pipette. The image of the liquid drop was captured by a video camera and then transferred to a computer screen.SEM imaging of the films were performed with Philips XL30 ESEM-FEG/EDAX. The specimens were prepared for SEM by freeze fracturing in liquid nitrogen and applying a gold coating before SEM analysis.

\section{Results and Discussion}

\subsection{FT-IR spectroscopy of the composites}

Figure 1 shows the FTIR spectra of pure TPU and TPU/ Barium metaborate composites. The thermoplastic polyurethane FTIR absorption bands at around $3325 \mathrm{~cm}^{-1}$ (-N-H stretching), $1525 \mathrm{~cm}^{-1}$ (-N-H deformation), and $1730 \mathrm{~cm}^{-1}(-\mathrm{C}=\mathrm{O})$ indicated the urethane structure. In addition, the peaks at $2917 \mathrm{~cm}^{-1}$ and $2959 \mathrm{~cm}^{-1}$ in the spectra can be attributed to the asymmetric and symmetric stretching vibrations of $-\mathrm{CH}$ bonds. ${ }^{16}$

\subsection{XRD analysis of the composites}

X-ray diffraction (XRD) traces for the TPU/ Barium metaborate composites are presented in Figure 2. It was previously determined that the characteristic XRD peak of thermoplastic polyurethane was at $2 \theta=21^{\circ} .{ }^{19}$ The characteristic XRD peak of barium metaborate $2 \theta=23^{\circ}-24^{\circ} .{ }^{20}$ XRD patterns of all the composite samples showed sharp peaks that barium metaborate particles were dispersed homogenously and they were buried inside the polymer matrix.

\subsection{Thermal properties of the composites}

Polymeric materials properties such as thermal stability and glass transition temperature $(\mathrm{Tg})$ are very important parameters for the composite materials applications. The glass transition temperatures $\left(T_{\mathrm{g}}\right)$ of the composites listed in Table 2 were determined by differential scanning calorimetry (DSC). The $T_{\mathrm{g}}$ 's of thermoplastic polyurethane (F0) is $-1^{\circ} \mathrm{C}$. All composites had $T_{\mathrm{g}}$ greater than $-1{ }^{\circ} \mathrm{C}$. The $T_{\mathrm{g}}$ of these composites are significantly $\left(15-35^{\circ} \mathrm{C}\right)$ higher than that of its thermoplastic polyurethane (F0) (Table 2). This situation can be attributed to the loss of mobility of the polymer chains due to the decrease in the free volume of the composites..$^{10}$ DSC results show that the addition of barium metaborate caused the $T_{\mathrm{g}}$ values of the composites to increase. For example, F1 has a $T_{\mathrm{g}}$ of $15^{\circ} \mathrm{C}$, while $\mathrm{F} 4$ has a $T_{\mathrm{g}}$ of $36.9^{\circ} \mathrm{C}$. The glass transition temperatures of the composites were found to be $25.3^{\circ} \mathrm{C}$ and $32.6^{\circ} \mathrm{C}$ for $\mathrm{F} 2$ and $\mathrm{F} 3$, respectively.

The thermal stabilities of composites were determined using TGA in a nitrogen atmosphere at a heating rate of

Table 2. Thermal characteristics of the TPU/ Barium metaborate composites.

\begin{tabular}{cccc}
\hline Sample & $\mathbf{T}_{\text {\%50 }}\left({ }^{\mathbf{0}} \mathbf{C}\right)$ & $\begin{array}{c}\mathbf{C h a r} \text { yield } \\
(\mathbf{\%})\end{array}$ & $\mathbf{T}_{\mathbf{g}}\left({ }^{\circ} \mathbf{C}\right)$ \\
\hline F0 & 368 & 1.7 & -1.0 \\
F1 & 366 & 5.0 & 15.0 \\
F2 & 357 & 15.6 & 25.3 \\
F3 & 358 & 18.8 & 32.6 \\
F4 & 375 & 22.9 & 36.9 \\
\hline
\end{tabular}




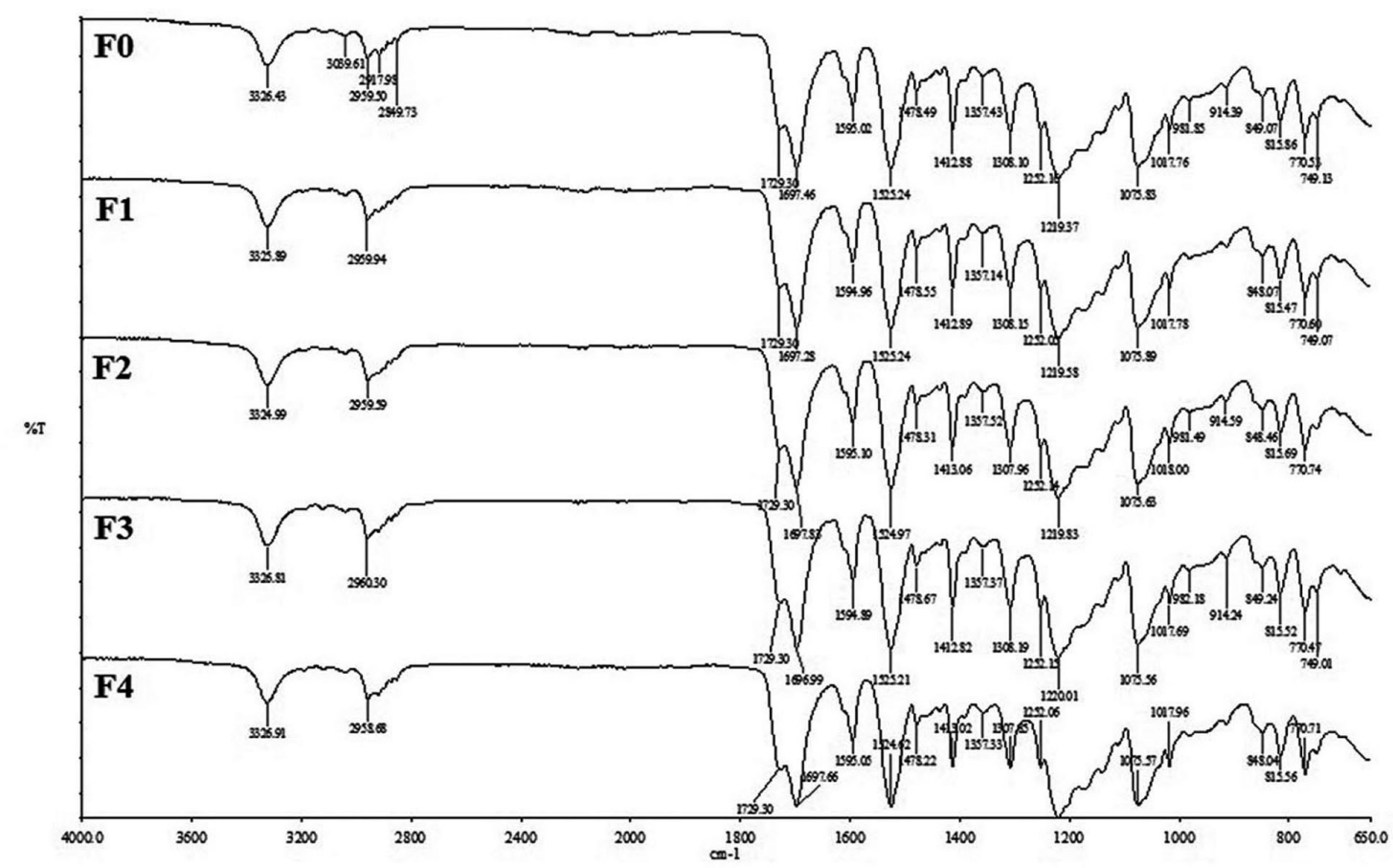

Figure 1. ATR-FTIR spectra of TPU and TPU/Barium metaborate composites.

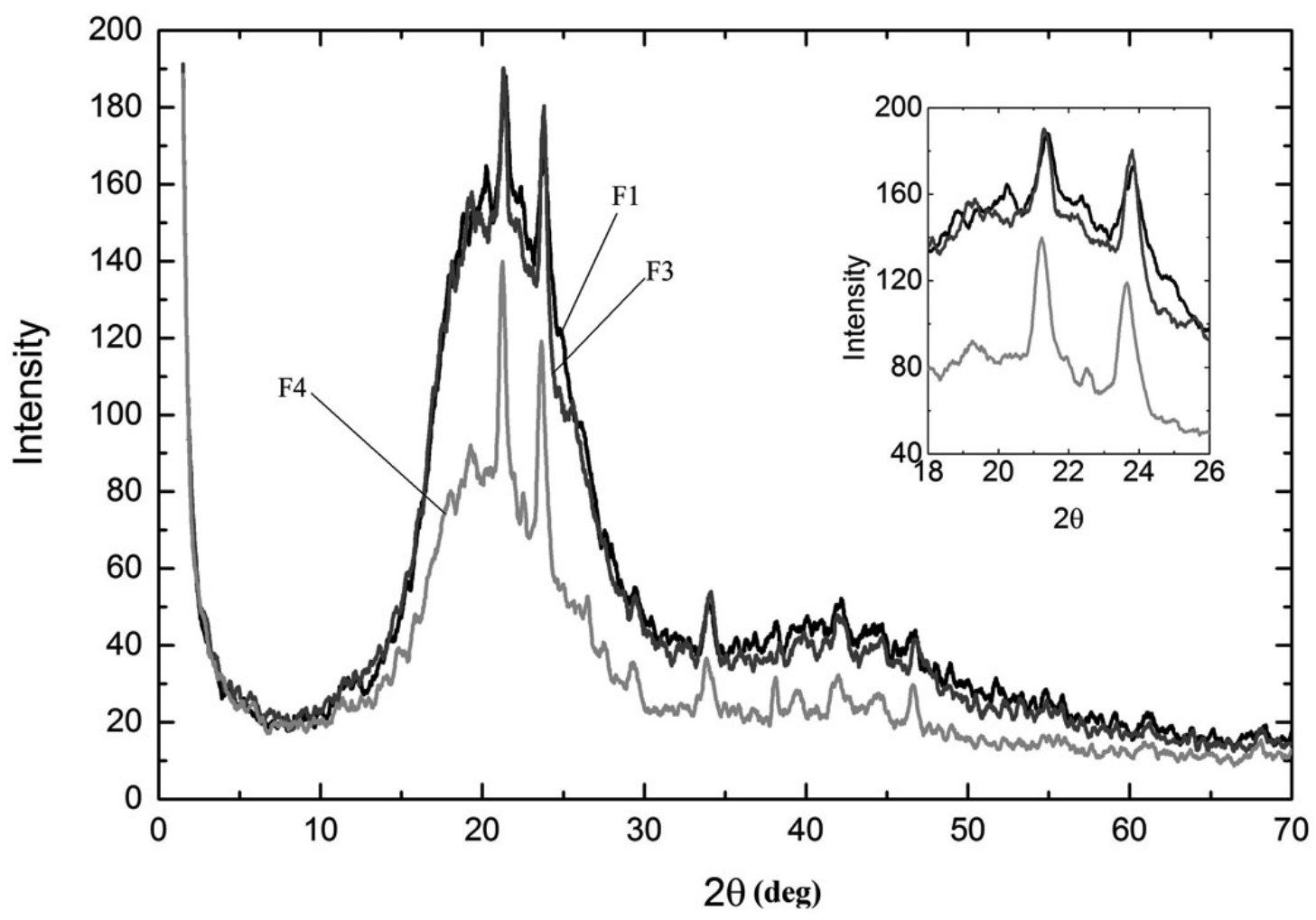

Figure 2. XRD patterns of the TPU/ Barium metaborate composites. 
$10^{\circ} \mathrm{C} / \mathrm{min}$ in Figure 3. Table 2 presents different weight loss temperatures of the composites. The char yields of the F0, F1, F2, F3 and F4 are found to be 1.7, 5.0, 15.6, 18.8 and 22.9, respectively. The higher the barium metaborate content in the composites, the more char residue is observed. Results of the TGA measurements indicated that the presence of the barium metaborate content clearly results in excellent thermal stability at high temperatures. Barium metaborate decomposed endothermically and released non-combustible

Table 3. Mechanical characteristics of the TPU/ Barium metaborate composites.

\begin{tabular}{cccc}
\hline Sample & $\begin{array}{c}\text { Modulus } \\
\text { (MPa) }\end{array}$ & $\begin{array}{c}\text { Strength at } \\
\text { break } \\
\text { (MPa) }\end{array}$ & $\begin{array}{c}\text { Elongation at } \\
\text { break } \\
\text { (\%) }\end{array}$ \\
\hline F0 & 30.9 & 12.2 & 12.6 \\
F1 & 33.4 & 13.7 & 19.5 \\
F2 & 52.1 & 17.1 & 23.1 \\
F3 & 58.9 & 23.4 & 26.9 \\
F4 & 47.8 & 20.3 & 24.9 \\
\hline
\end{tabular}

gas; barium metaborate has great potential to act as fire retardant fillers in polymer materials. ${ }^{8}$

\subsection{Mechanical properties of the composites}

The mechanical properties of TPU and TPU/Barium metaborate composite films with the barium metaborate contents of $1,3,5$, and $7 \mathrm{wt} \%$ are depicted in Table 3 . The mechanical properties of TPU composites was first increased (F1, F2, F3) with the addition barium metaborate. But as the barium metaborate percentage increased (F4) in the formulations, an decrease in the mechanical properties was observed and this situation is attributed to the agglomeration of the barium metaborate.

\subsection{Surface properties of the composites}

The surface properties of the composites were investigated by water contact angle measurements. Each contact angle value is given in Figure 4 which represents an average of 5 readings. $\mathrm{F} 0$ has a contact angle of $71^{\circ}$. Contact angles changed as $77^{\circ}, 81^{\circ}, 83^{\circ}$ and $85^{\circ}$ for $\mathrm{F} 1$,
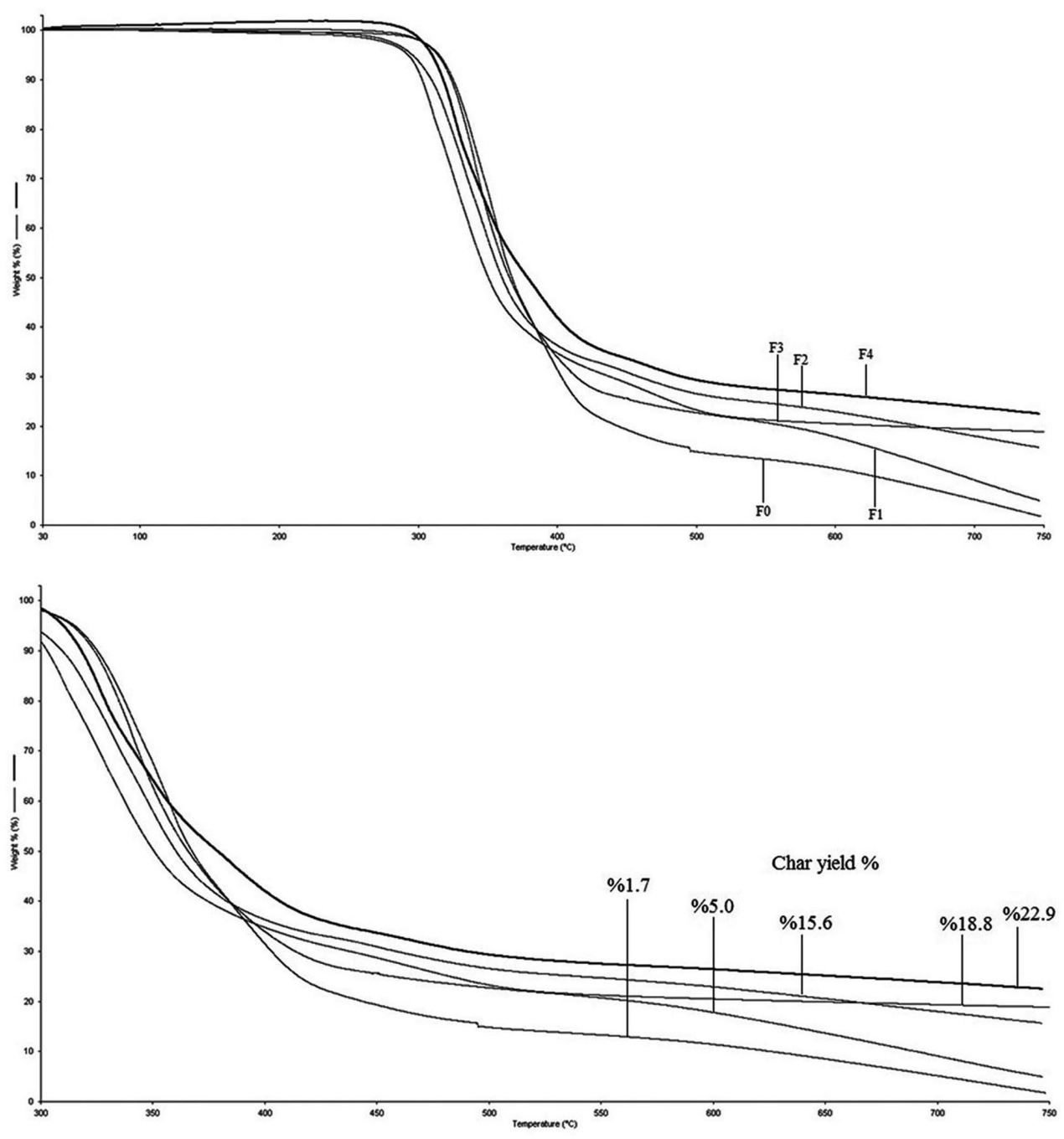

Figure 3. TGA curves of TPU/Barium metaborate composites with different barium metaborate content at nitrogen atmosphere. 
F2, F3 and F4, respectively. The contact angle values of the composites increased with increasing amount of barium metaborate.

\subsection{Morphology of the composites}

The morphology of composites was observed by scanning electron microscopy (SEM).Figure 5a-g presents SEM images of the fractured surface of (a) F0 (5000x), (b) F0 (10000x), (c) F1 (20000x), (d) F1 (50000x), (e) F4 (350x), (f) F4 (2000x) and (g) F4 (50000x), respectively. As it can be seen in Fig. 5a-b, pure TPU film has a smooth, homogeneous surface. In Figure 5c-d it can be observed that

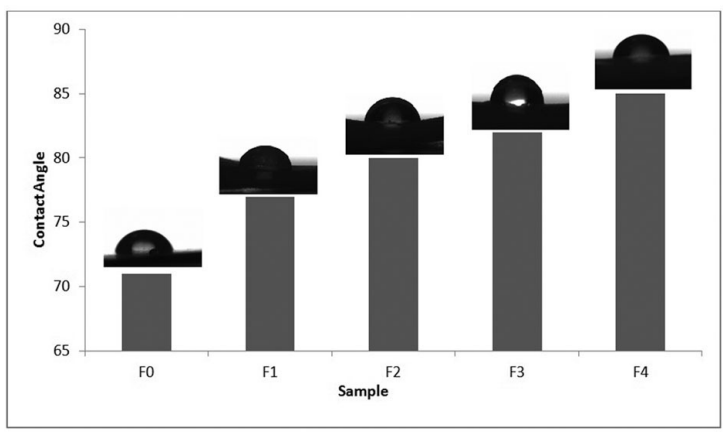

Figure 4. Contact angle values of the TPU/ Barium metaborate composites. barium metaborate particles are homogenously dispersed throughout the TPU matrix. According to micrographs it can be clearly seen that the barium metaborate particle diameters look almost same. This result can be attributed to the fact that the composites showed a good interaction interface between the barium metaborate particles and the TPU polymer. As it is shown in Figure 5e-f-g the combination of smaller particles leads to the formation of larger aggregates that is caused by the increase in particle number.

\section{Conclusions}

In this study, our aim was to prepare thermoplastic polyurethane (TPU) composite materials with improved thermal stability. Thermal analysis was clearly demonstrated that the composites of TPU/ barium metaborate have better thermal stability than pure TPU. It was observed that, as the amount of barium metaborate was increased in the composites, the thermal stability increased. The glass transition temperatures of the composites were increased with the addition of barium metaborate, and it could be attributed due to the decrease in the segmental motion of the polymer chains. SEM micrographs showed that barium metaborate particles were dispersed homogeneously in thermoplastic polyurethane. We reach the conclusion that barium metaborate has a great potential to act as fire retardant fillers in polymer materials.
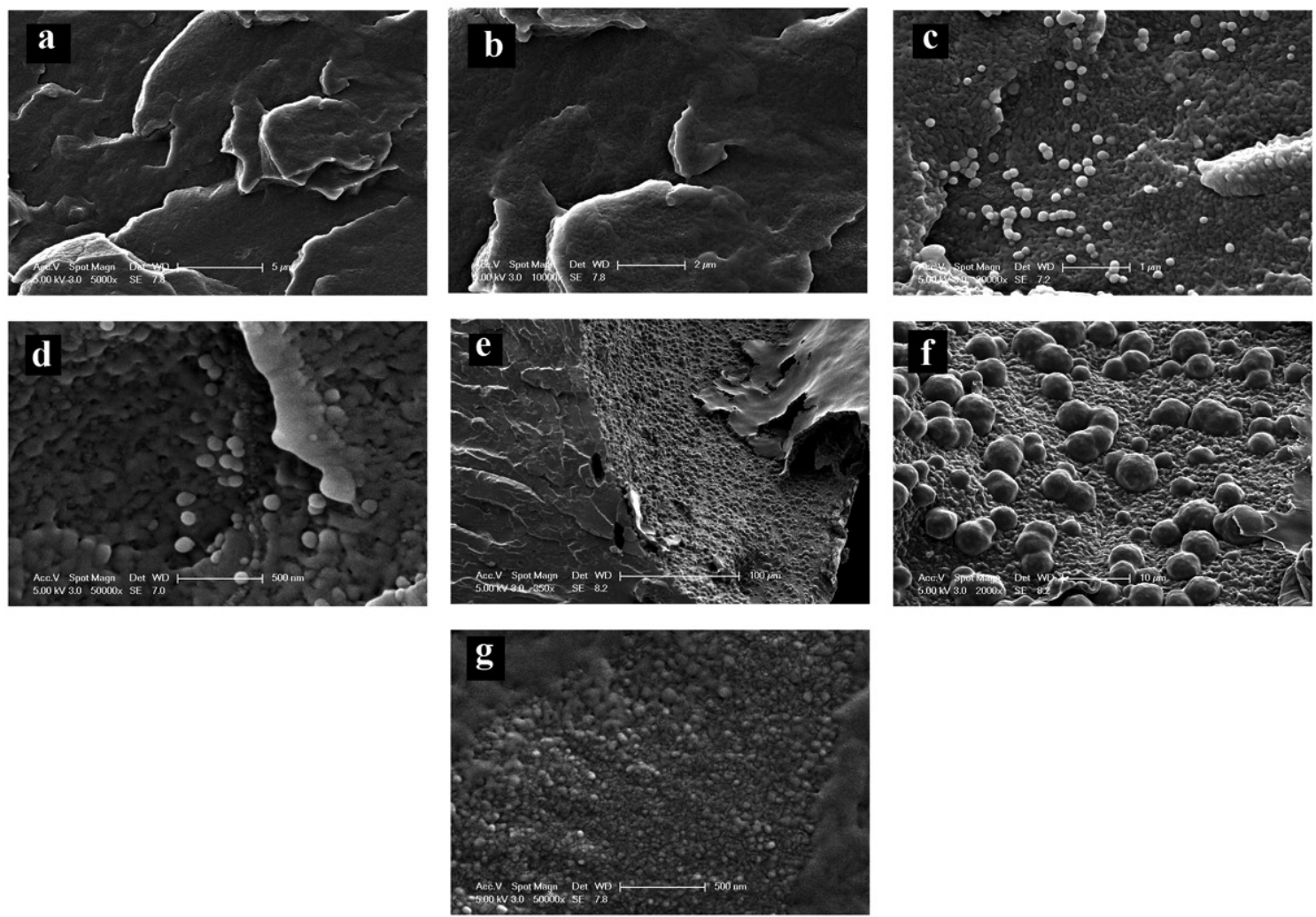

Figure 5. SEM micrographs of the TPU/ Barium metaborate composites: (a) F0 (5000x), (b) F0 (10000x), (c) F1 (20000x), (d) F1 (50000x), (e) F4 (350x), (f) F4 (2000x) and (g) F4 (50000x). 


\section{References}

1. Moreland JC, Wilkes GL, Turner RB. Segmental orientation behavior of flexible water-blown polyurethane foams. Journal of Applied Polymer Science.1991;43:801-815. DOI: 10.1002/ app.1991.070430419

2. Russo P, Lavorgna M, Piscitelli F, Acierno D, Di Maio L. Thermoplastic polyurethane films reinforced with carbon nanotubes: The effect of processing on the structure and mechanical properties. European Polymer Journal. 2013;49(2):379-388. DOI: $10.1016 /$ j.eurpolymj.2012.11.008

3. Tabuani D, Bellucci F, Terenzi A, Camino G. Flame retarded Thermoplastic Polyurethane (TPU) for cable jacketing application. Polymer Degradation and Stability.2012;97(12):2594-2601. DOI: 10.1016/j.polymdegradstab.2012.07.011

4. Stribeck N, Zeinolebadi A, Harpen F, Luinstra G, Eling B, Botta S. Thermoplastic polyurethane cross-linked by functionalized silica. nanostructure evolution under mechanical load. Macromolecules. 2013;46(10):4041-4052. doi:10.1021/ma400512b

5. Koerner H, Liu W, Alexander M, Mirau P, Dowty H, Vaia RA. Deformation-morphology correlations in electrically conductive carbon nanotube-thermoplastic polyurethane nanocomposites. Polymer. 2005;46:4405-4420. doi:10.1016/j.polymer.2005.02.025

6. Alves P, Coelho J, Haack J, Rota A, Bruinink A, Gil H. Surface modification and characterization of thermoplastic polyurethane. European Polymer Journal. 2009;45(5): 1412-1419. doi.10.1016/j. eurpolymj.2009.02.011.

7. Chen R, Huang C, Ke Q, He C, Wang H, Mo X. Preparation and characterization of coaxial electrospun thermoplastic polyurethane/collagen compound nanofibers for tissue engineering applications. Colloids and Surfaces B: Biointerfaces. 2010;79(2): 315-325. doi./10.1016/j.colsurfb.2010.03.043.

8. Madakbaş S, Çakmakçı E, Kahraman MV. Preparation and thermal properties of polyacrylonitrile/hexagonal boron nitride composites. Thermochimica Acta. 2013; 552:1-4. doi. org/10.1016/j.tca.2012.11.011.

9. Madakbaş S, Çakmakçı E, Kahraman MV, Esmer K. Preparation, characterisation, and dielectric properties of polypyrrole-clay composites. Chemical Papers. 2013;67(8):1048-1053.doi. org/10.2478/s11696-012-0279-3.

10. Qi K, Zhang G. Effect of organoclay on the morphology, mechanical, and thermal properties of polyimide/organoclay nanocomposite foams. Polymer Composites. 2014; 35(12):23112317. doi.org/10.1002/pc.22895.

11. Im H, Roh SC, Kim CK. Characteristics of thermoplastic polyurethane composites containing surface treated multiwalled carbon nanotubes for the underwater applications. Macromolecular Research. 2013;21(6):614-623. doi.org/ 10.1007/s13233-0131073-y.

12. Vajrasthira $C$, Amornsakchai $T$, Limcharoen SB. Fiber-matrix interactions in aramid-short-fiber-reinforced thermoplastic polyurethane composites. Journal of Applied Polymer Science. 2003;87(7):1059-1067. doi.org/10.1002/app.11484.

13. Sapuan SM, Pua FL, El-Shekeil YA, AL-Oqla FM. Mechanical properties of soil buried kenaf fibre reinforced thermoplastic polyurethane composites. Materials \& Design. 2013;45(48):467470. doi.org/10.1016/j.matdes.2013.03.013.

14. Osman AF, Edwards GA, Schiller TL, Andriani Y, Jack KS, Morrow IC, et al. Structure-property relationships in biomedical thermoplastic polyurethane nanocomposites. Macromolecules. 2012;45(1):198-210. doi.org/10.1021/ma202189e.

15. Park JH, Dao TD, Lee HI, Jeong HM, Kim BK. Properties of graphene/shape memory thermoplastic polyurethane composites actuating by various methods. Materials. 2014;7(3):1520-1538. doi.org/10.3390/ma7031520.

16. Çakmakçı E, Koçyiğit Ç, Çakır S, Durmuş A, Kahraman MV. Preparation and characterization of thermally conductive thermoplastic polyurethane/h-BN nanocomposites. Polymer Composites. 2014;35(3):530-538. doi.org/10.1002/pc.22692.

17. Baral D, De PP, Nando G. Thermal characterization of mica-filled thermoplastic polyurethane composites. Polymer Degradation and Stability. 1999;65(1):47-51. doi.org/10.1016/ S0141-3910(98)00215-8.

18. Klyosov AA. Wood-Plastic composites. New York: WileyInterscience; 2007. ISBN-13: 978-0470148914.

19. Koerner H, Kelley JJ, Vaia RA. Transient microstructure of low hard segment thermoplastic polyurethane under uniaxial deformation. Macromolecules. 2008;41(13): 4709-4716. doi. org/10.1021/ma800306z.

20. Chen S, Zhang S, Zhou X, Wen Z. Preparation and properties of the barium borate glassy matrix composite materials containing fused silica and monoclinic zirconia. Journal of Alloys and Compounds. 2011;509:4848-4853. doi.org/10.1016/j. jallcom.2011.01.188. 